\title{
The Rice Bacterial Blight Resistance Gene xa5 Encodes a Novel Form of Disease Resistance
}

\author{
Anjali S. Iyer, and Susan R. McCouch \\ Department of Plant Breeding and Genetics, 240 Emerson Hall, Cornell University, Ithaca NY 14853, U.S.A.
}

Submitted 22 June 2004. Accepted 30 August 2004.

\begin{abstract}
The rice $x a 5$ gene for disease resistance to Xanthomonas oryzae pv. oryzae has been positionally cloned and encodes the gamma subunit of transcription factor IIA (TFIIA $\gamma$ ). TFIIA $\gamma$ is a general eukaryotic transcription factor with no previously known role in disease resistance. $x a 5$ is unusual in that it is recessive and does not conform to one of the typical resistance gene structural classes. Sequencing of TFIIA $\gamma$ in resistant and susceptible isolines revealed two nucleotide substitutions resulting in an amino acid change between resistant and susceptible cultivars. This association was conserved across 27 resistant and nine susceptible rice lines in the Aus-Boro group.
\end{abstract}

Additional keywords: Oryzae sativa, positional cloning, $R$ gene.

Within the past 10 years, substantial plant research has been devoted to the study of plant disease resistance $(R)$ genes. These genes encode products that provide resistance upon direct or indirect interaction with cognate pathogen avirulence (avr) gene products (Flor 1971). Most of the effort in this area of research has focused on dominant $R$ genes and their corresponding pathways. Indeed, of the more than 40 disease $(R)$ genes cloned, all but two are dominant (Martin et al. 2003). Nearly all of these fall into five classes, the most common being the nucleotide binding site-leucine-rich region (NBSLRR) (Martin et al. 2003), and the majority result in resistance only to specific races of pathogens expressing the corresponding avr or race-specific resistance.

In contrast to resistance conferred by dominant $R$ genes, little is known regarding recessive disease resistance. $x a 5$ is a recessive, race-specific $R$ gene that provides immunity to races of Xanthomonas oryzae pv. oryzae expressing avrxa5, the cognate avirulence gene to $x a 5$. X. oryzae pv. oryzae causes rice bacterial blight, a severe disease in South and Southeast Asia. Avrxa5 is likely to be a member of the AvrBs3 family of proteins (Bai et al. 2000; Hopkins et al. 1992), which are usually characterized by nuclear localization signals and transcriptional activation domains (Bonas and Lahaye 2002).

$x a 5$ is a naturally occurring mutation that is most commonly found in the Aus-Boro group of rice (Oryzae sativa L.) varieties from the Bangladeshi region of Asia (Garris et al. 2003).There are over 20 resistance genes to $X$. oryzae pv. oryzae, three of which have been cloned (Xa21, Xal, and Xa26) and fall into

Corresponding author: S. R. McCouch; Telephone: +1-607-255-0420; Fax: +1-607-255-6683; E-mail: srm4@ cornell.edu

Nucleotide sequence data is available under the following accession numbers: susceptible haplotype 1, AY643717; IR24 BAC (containing susceptible haplotype), AF532975; gi:28195112 resistant haplotype, AY643716. one of the five typical $R$ gene classes (Song et al. 1995; Sun et al. 2004; Yoshimura et al. 1998). Xa21 and Xa26 both encode NBS-LRR proteins containing a kinase domain, while Xal encodes a member of the NBS-LRR class.

$x a 5$ does not resemble either of the two cloned recessive resistance genes in plants, mlo or RRS1-R. In contrast to $x a 5$, resistance governed by barley mlo is not race-specific (Buschges et al. 1997). Mutations in Mlo result in immunity to nearly all isolates of the fungal pathogen Erysiphe graminis f. sp. hordei. The RRS1-R gene from Arabidopsis provides resistance to several strains of Ralstonia solanacearum and encodes an NBSLRR protein with a WRKY motif characteristic of some plant transcription factors (Deslandes et al 2002). The RRS1-R gene product physically interacts with its cognate protein PopP2 (Deslandes et al. 2003). Unlike $x a 5, R R S 1-R$ shares many characteristics with dominant $R$ genes (Deslandes et al. 2003). For example, while genetically defined as recessive, $R R S 1-R$ behaves as a dominant gene in transgenic plants and is a member of the NBS-LRR $R$ gene class.

Here, we report the cloning of xa5. This novel disease $R$ gene provides adult plant resistance and encodes the gamma subunit of transcription factor IIA (TFIIA $\gamma$ ), one of several general transcription factors responsible for accurate transcription by RNA polymerase II (Orphanides et al. 1996).

\section{RESULTS}

Positional cloning identifies $x a 5$

in an 8.1-kb region containing TFIIA $\gamma$.

Previous results in our lab had narrowed $x a 5$ to an approximately $100-\mathrm{kb}$ segment in the subtelomeric region of chromosome 5 (Blair et al. 2003). A screen of approximately 2,345 F2 individuals from a cross between susceptible IR24 and resistant IRBB5 identified 27 recombinants within the 100-kb region between microsatellite markers RM601 and RM611. Of $\mathrm{t}$ individuals, 14 had recombination breakpoints between RM601 and RM603, two had breakpoints between RM603 and RM607, seven between RM607 and RM609, and four between RM609 and RM611 (Fig. 1).

To further narrow the region containing the critical recombination breakpoint, single nucleotide polymorphisms (SNP) were identified in the region between the recombinant markers. Once the breakpoint had been isolated to a pair of SNP, the 5-kb region between these was sequenced. F2 individual 3E9 had heterozygous (susceptible) sequence at RM603 and (resistant) IRBB5 sequence at RM607. The recombination breakpoint in this individual was upstream of the ABC transporter and TFIIA $\gamma$, which are transcribed from opposite strands (Fig. 1). F3 individuals derived from 3-E9 were all resistant, indicating that the $x a 5$ gene was located proximal $\left(3^{\prime}\right)$ of the breakpoint in the IRBB5 sequence. 
Individual 17-H7 had heterozygous (susceptible) sequence at RM603 and (resistant) IRBB5 sequence at RM607. The heterozygous sequence continued from RM603 until a breakpoint in the second exon of TFIIA $\gamma$ (Fig. 1), after which the sequence was homozygous IRBB5. F3 family members derived from this individual were all resistant.

Individual 10-D9 had IR24 (susceptible) sequence at RM603 and RM607. This sequence continued until approximately $2.2 \mathrm{~kb}$ downstream of the $3^{\prime}$ untranslated region (UTR) of TFIIA $\gamma$ and, subsequently, was heterozygous. While all members of this F3 family had homozygous IR24 (susceptible) sequence until this breakpoint, one-quarter were homozygous for IRBB5 (resistant) after the breakpoint. When inoculated, all members of family 10-D9 were susceptible, indicating that the $x a 5$ gene was located distal $\left(5^{\prime}\right)$ of the recombination breakpoint (Fig. 1).

Additional recombinants confirmed that $x a 5$ was located in this region. Individual 7-E3 had IR24 (susceptible) sequence at RM603 and RM607 and heterozygous sequence at RM609. Sequencing revealed that this individual had a recombination breakpoint in the middle of the gene encoding the hypothetical protein Q94HL4. Thus one-quarter of F3 family members had homozygous IR24 sequence from RM607 until the middle of the coding region of this gene, whereupon the sequence became homozygous IRBB5. Members of this family were all susceptible, demonstrating that the $x a 5$ gene was distal $\left(5^{\prime}\right)$ of this breakpoint, consistent with our other findings.

As all individuals in family 10-D9 were susceptible and all members in family $17-\mathrm{H} 7$ were resistant, the $x a 5$ gene was localized between the recombinant breakpoints of these two families. The breakpoints encompassed approximately $5.9 \mathrm{~kb}$ of TFIIA $\gamma$ and $2.2 \mathrm{~kb}$ of downstream intergenic sequence on the IR24 bacterial artificial chromosome (BAC) (Fig. 1).

Sequencing and expression analysis of the gene encoding hypothetical protein Q94HL4 reveals no differences between susceptible and resistant cultivars. To fully evaluate a possible role of the 2.2-kb region downstream of TFIIA $\gamma$ in regulating the expression of $Q 94 H L 4$, we first sequenced the coding region of the Q94HL4 hypothetical protein and found it to be identical between IR24 (susceptible) and IRBB5 (resistant) isolines. We then used the PLACE promoter prediction program (Higo et al. 1999) to scan the 2.2-kb region for enhancer elements in IR24, in the internationally sequenced susceptible japonica variety Nipponbare (The Rice Choromosome $10 \mathrm{Se}$ quencing Consortium 2003), and in IRBB5 (resistant). No enhancer elements were found that segregated with susceptible and resistant phenotypes. There were 26 polymorphisms within this $2.2-\mathrm{kb}$ region, including a $327-\mathrm{bp}$ fragment that was absent in IRBB5 but present in IR24 (Table 1), Of these however, 18 (including the 327-bp indel) were shared between IRBB5 (resistant) and the susceptible japonica Nipponbare, suggesting that they are not involved in the resistance conferred by $x a 5$.

To investigate the possible functional significance of the polymorphisms in this region, we compared the expression patterns of both Q94HL4 and TFIIA $\gamma$ in susceptible and resistant plants, with and without inoculation with race 2 of $X$. oryzae pv. oryzae. Reverse transcription-polymerase chain reaction (RT-PCR) analysis showed that transcripts from both Q94HL4 and TFIIA $\gamma$ were detectable in resistant and susceptible cultivars at all timepoints and in wounded controls (Fig. 2). With no difference in the coding sequence of Q94HL4 and similar expression between the resistant and susceptible isolines and given the position of the breakpoint in recombinant 10-D9, we concluded that there was no evidence to merit further consideration of $Q 94 H L 4$ as $x a 5$. These results left open the possibility that a mutation in the coding region of TFIIA $\gamma$ was responsible for $x a 5$ resistance.

\section{Sequencing of TFIIA $\gamma$ reveals two nucleotide substitutions} that result in a single amino acid change.

The start codon, splice junctions, and 3' UTR of the TFIIA $\gamma$ gene were defined by aligning a Nipponbare TFIIA $\gamma$ cDNA (GI 32975200) to the IR24 (susceptible) BAC. We then sequenced the coding region of TFIIA $\gamma$ in the resistant IRBB5 isoline and compared it with the IR24 sequence. This identified two nucleotide substitutions resulting in an amino acid substitution from valine to glutamic acid at position 39 in the

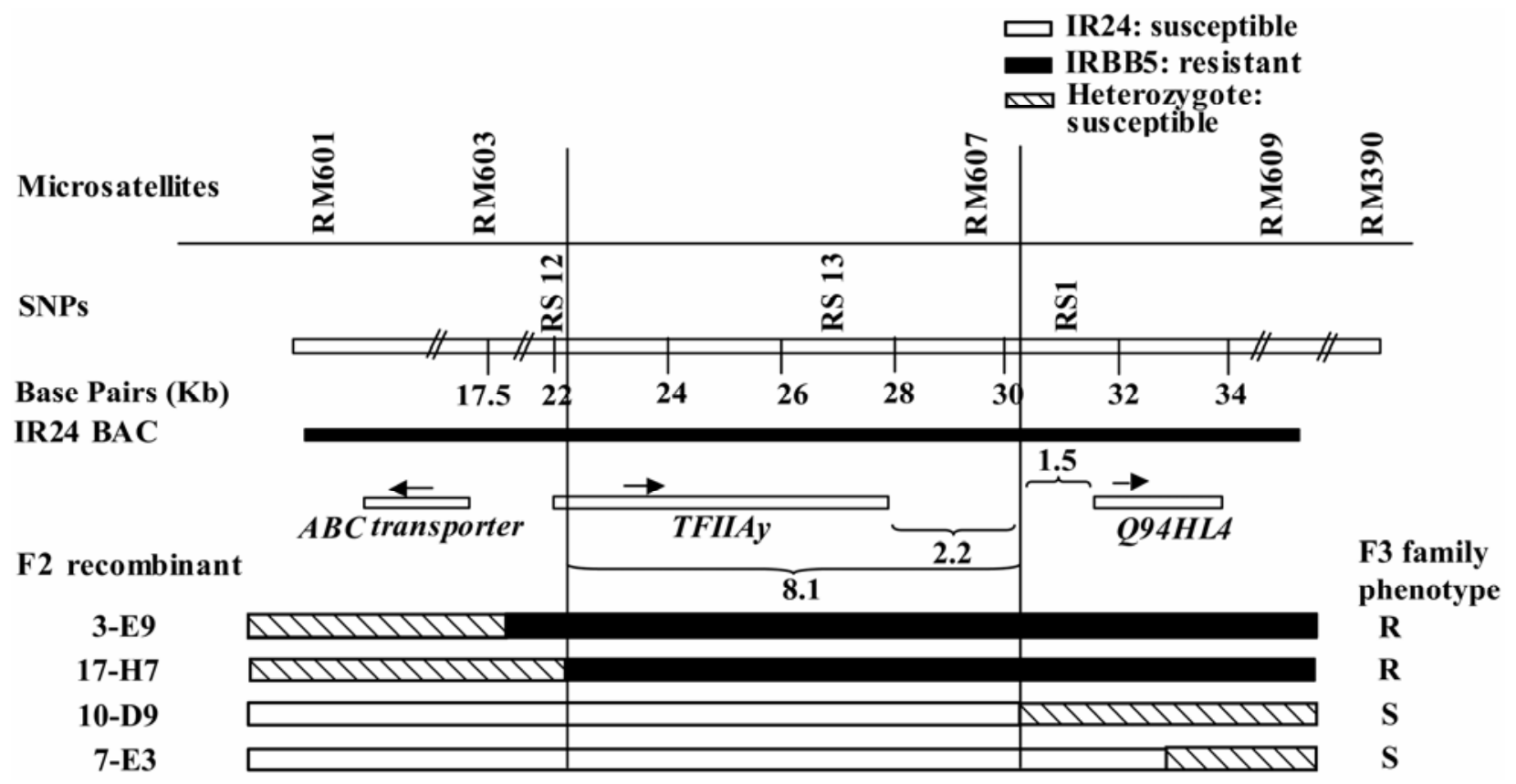

Fig. 1. Relevant recombinants within the region containing $x a 5$ that allowed narrowing of the region to approximately $8.1 \mathrm{~kb}$ containing only $T F I I A \gamma$. Arrows indicate the direction of transcription. SNPs = single nucleotide polymorphisms, $\mathrm{R}=$ resistant, and $\mathrm{S}=$ susceptible. Base pairs refer to relative distances along the IR24 bacterial artificial chromosome (BAC). 
resistant cultivar, a significant change from a hydrophobic to hydrophilic amino acid (Fig. 3A). There were also five singlebase pair substitutions between IR24 (susceptible) and IRBB5 (resistant) within the 380-base pair 3' UTR. However, all five of these substitutions were identical in Nipponbare (susceptible)

Table 1. Polymorphisms within the 2.2-kb intergenic region downstream of $x a 5$

\begin{tabular}{lll}
\hline IR24 $^{\text {a }}$ & Nipponbare & \multicolumn{1}{c}{ IRBB5 } \\
\hline A & G & G \\
AG & deleted & deleted \\
T & C & C \\
C* & C & T \\
A & deleted & deleted \\
327 bp insertion & deleted & deleted \\
T & G & G \\
A & G & G \\
T & C & C \\
T & C & C \\
TATT & deleted & CA-- \\
C & T & T \\
CA & TT & TT \\
C & G & G \\
deleted & GTGAGT & GTGAGT \\
G & A & A \\
AGAGG* & AGAGG & G--- \\
deleted & TGCTGTGCTC & TGCTGTGCTC \\
T & C & C \\
$G^{*}$ & G & T \\
A & T & T \\
T* & T & C \\
$G^{*}$ & G & C \\
C* & C & T \\
gat* & gat & aga \\
A* & A & T \\
\hline
\end{tabular}

${ }^{a}$ Polymorphisms between susceptible cultivars IR24 and Nipponbare and resistant IRBB5 in the 2.2-kb region, presented sequentially from the end of the Nipponbare TFIIA $\gamma$ cDNA (GI 32975200) to the nearest recombinant breakpoint. Asterisks indicate the eight polymorphisms that segregate for susceptibility. and IRBB5 (resistant), indicating that they do not play a role in $x a 5$ resistance.

Examination of the structure of TFIIA $\gamma$ further showed that the variable amino acid at position 39 resided in a solventexposed surface, suggesting that it may play a role in proteinprotein interactions (Bleichenbacher et al. 2003). This single amino acid change in TFIIA $\gamma$ is consistent with the stable expression of this gene in both susceptible and resistant plants and leads to the hypothesis that it functions both as general transcription factor and as $x a 5$.

\section{Association between haplotype and phenotype.}

To further explore the association between this amino acid polymorphism and the phenotype, we sequenced the region of TFIIA $\gamma$ around the nucleotide substitutions in 27 resistant and nine susceptible accessions from the group of Aus-Boro rice varieties (Blair and McCouch 1997). We also examined this association in the susceptible japonica variety Nipponbare. Sequenced varieties are listed in Table 2. All nine susceptible Aus-Boro varieties and seven of the 27 resistant varieties were previously assayed with $X$. oryzae pv. oryzae race 2 in our laboratory (Garris et al. 2003), while the remaining 20 resistant accessions had previously been allele-tested for xa5 (Olufowote et al. 1977; Sidhu et al. 1978; Singh et al. 1983). In addition, Nipponbare was tested using the same assay and was confirmed susceptible. We found a single resistant haplotype conserved across all 27 resistant lines. There were two haplotypes among the 11 susceptible accessions, each of which carried nucleotides that would result in a valine at position 39. The japonica Nipponbare as well as four of the Aus-Boro lines contained the same susceptible haplotype as IR24, while five Aus-Boro lines had a silent mutation within the coding region (Fig. 3B).

\section{DISCUSSION}

Using several key experimental observations, we have shown that $x a 5$ encodes TFIIA $\gamma$. First, a collection of individuals

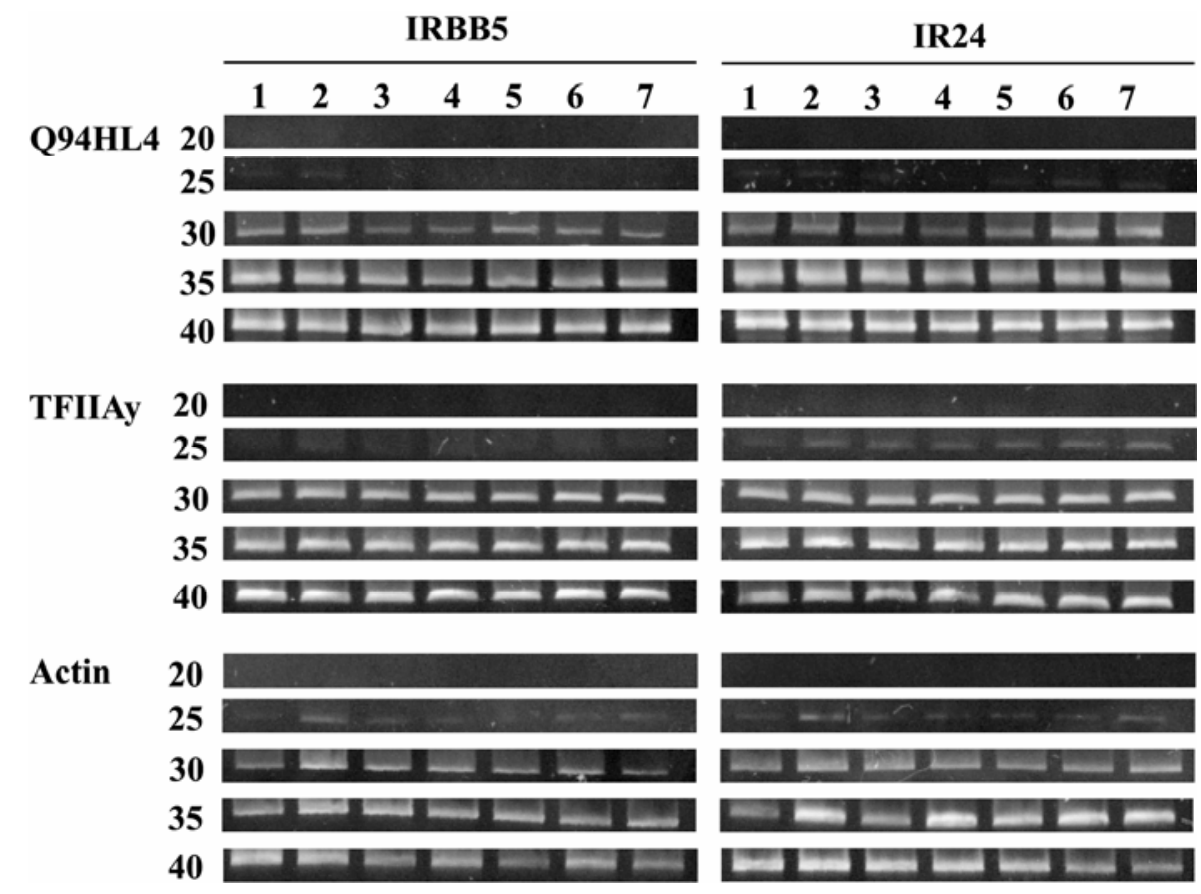

Fig. 2. Reverse transcription-polymerase chain reaction (RT-PCR) analysis of TFIIA $\gamma$ and $Q 94 H L 4$. The experiment was repeated three times, and typical results are shown. A series of 20, 25, 30, 35, and 40 cycles of amplification was used for the PCR. Lane 1, uninoculated plants; lane 2, 2 h postwounding; lane 3, 2 h postinoculation (PI) with Xanthomonas oryzae pv. oryzae PXO 86; lane 4, 4 h PI; lane 5, 8 h PI; lane 6, 24 h PI; and lane 7, 48 h PI. 
recombinant between resistant and susceptible parents allowed us to narrow the region to an approximately $8.1-\mathrm{kb}$ interval containing the gamma subunit of TFIIA. This region was located $1.5 \mathrm{~kb}$ upstream of the gene encoding the hypothetical protein Q94HL4. Sequencing and expression analysis eliminated Q94HL4 from further consideration but identified a single amino acid change within the coding region of TFIIA $\gamma$ that distinguished the resistant and susceptible isolines and would not affect the expression TFIIA $\gamma$. Third, sequencing of 27 resistant and nine susceptible cultivars in the Aus-Boro group demonstrated a perfect association between the haplotype of E39 and resistance to race 2 of $X$. oryzae pv. oryzae. Together, these lines of evidence demonstrate that TFIIA $\gamma$ encodes the $x a 5$ resistance gene.
TFIIA is one of a set of general transcription factors required for transcription by RNA polymerase II (Orphanides et al. 1996). The functional molecule is composed of two subunits in yeast and three in plants and humans. TFIIA is essential to cell growth and has been shown to have several roles in transcription, including stimulation and stabilization of the interaction between the TATA-box binding protein and the general transcription factor TFIID, promoter selection, gene-specific regulation, and activator-dependent transcription (Hampsey et al. 1998; Orphanides et al. 1996).

The Drosophila genome has two copies of TFIIA $\gamma$ (Aoyagi and Wassarman 2000). In Drosophila spp., one copy is expressed only in particular tissue types (Zeidler et al. 1996). xa5 is $50 \%$ identical to the Drosophila and human TFIIA $\gamma$ sub-

\section{A \\ IRBB5: MATFELYRRSTIGMCLTETLDEMVSSGTLSPELAIQVLEQFDKSMTEALENQVKSKVSIKGH IR24: MATFELYRRSTIGMCLTETLDEMVSSGTLSPELAIQVLVQFDKSMTEALENQVKSKVSIKGH}

\section{IRBB5: LHTYRFCDNVWTFILTEASFKNEETTEQVGKVKIVACDSKLLSQ \\ IR24: LHTYRFCDNVWTFILTEASFKNEETTEQVGKVKIVACDSKLLSQ}

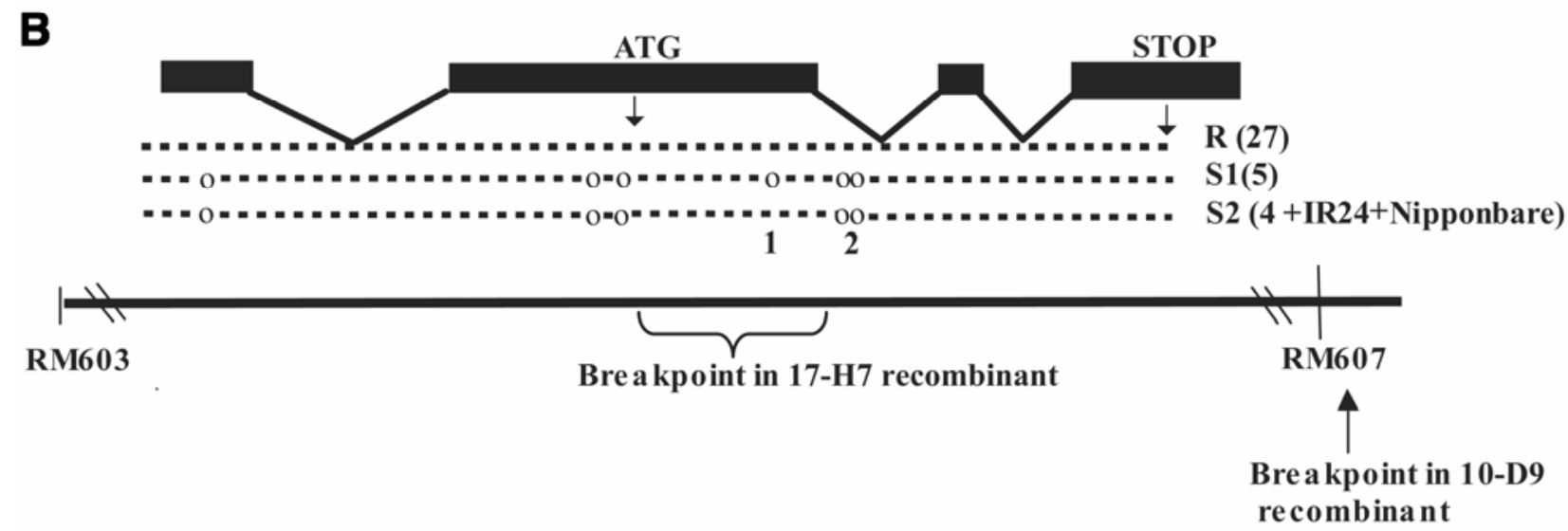

Fig. 3. The protein sequence, gene structure, and resistant and susceptible haplotypes of TFIIA $\gamma$. A, Resistant and susceptible TFIIA $\gamma$ sequences from isolines IRBB5 and IR24, respectively. All amino acids are identical, except the substitution at position 39 (indicated with an arrow and italicized) in exon 2. B, Resistant and susceptible haplotypes in the four exons of rice TFIIA $\gamma$. Dashes represent stretches of common nucleotides in the cDNA, circles represent the single nucleotide polymorphisms. All nucleotides in this region in isolines IR24 (S) and IRBB5 (R) and in the japonica subspecies Nipponbare (S) are identical except the circles. Numbers in parentheses indicate the number of Aus-Boro rice varieties sequenced with this genotype. $\mathrm{R}=$ resistant to race 2 of Xanthomonas oryzae pv. oryzae, $\mathrm{S} 1=$ first haplotype susceptible to race 2 of $X$. oryzae pv. oryzae, $\mathrm{S} 2=$ second haplotype susceptible to race 2 of $X$. oryzae pv. oryzae. 1 = silent nucleotide substitution: CTT (leucine) changed to CTC (leucine). 2 = functional nucleotide polymorphism: GTC (valine in susceptible varieties) changed to GAG (glutamic acid in resistant varieties).

Table 2. Aus-Boro varieties used in the association experiment

\begin{tabular}{|c|c|c|c|c|c|}
\hline Variety name & Accession number & Haplotype & Variety name & Accession number & Haplotype \\
\hline Aus 251 & IRGC 29043 & $\mathrm{R}$ & Garia & IRGC 25854 & $\mathrm{R}$ \\
\hline Ausha Boro & IRGC 27508 & $\mathrm{~S} 1$ & Ghuni Boro & IRGC 27515 & $\mathrm{~S} 2$ \\
\hline Badal & IRGC 37362 & $\mathrm{R}$ & $\mathrm{IRBB}^{\mathrm{a}}$ & PI 597068 & $\mathrm{R}$ \\
\hline Bageri & IRGC 16193 & $\mathrm{R}$ & Kal Shoni & IRGC 64780 & $\mathrm{R}$ \\
\hline Battiboro & IRGC37005 & $\mathrm{S} 1$ & Kaliboro & IRGC 29367 & $\mathrm{R}$ \\
\hline Boro & IRGC49159 & $\mathrm{S} 1$ & Kiomurali & IRGC 49222 & $\mathrm{R}$ \\
\hline Chaikon Shoni & IRGC 64771 & $\mathrm{R}$ & Lakhi Jhota & IRGC34711 & $\mathrm{S} 2$ \\
\hline DB3 & IRGC 8631 & $\mathrm{R}$ & Laksmilota & IRGC 27564 & $\mathrm{R}$ \\
\hline Devarasi & IRGC 16173 & $\mathrm{R}$ & Lal Ahu & IRGC 16121 & $\mathrm{R}$ \\
\hline DF1 & IRGC 8365 & $\mathrm{R}$ & Lal Sar & IRGC 16185 & $\mathrm{R}$ \\
\hline Dharia & IRGC 64773 & $\mathrm{R}$ & Matury & IRGC 16190 & $\mathrm{R}$ \\
\hline Dholi Boro & IRGC 27513 & $\mathrm{~S} 1$ & Mery & IRGC 34722 & $\mathrm{~S} 2$ \\
\hline DNJ142 & IRGC 8426 & $\mathrm{R}$ & Pankiraj & IRGC 24139 & $\mathrm{R}$ \\
\hline DV139 & IRGC 8870 & $\mathrm{R}$ & Rakhoil & IRGC 64793 & $\mathrm{R}$ \\
\hline DV32 & IRGC 8818 & $\mathrm{R}$ & Sanjani & IRGC 16177 & $\mathrm{R}$ \\
\hline DV85 & IRGC 8839 & $\mathrm{R}$ & Shaitan Dumra & IRGC 25921 & $\mathrm{~S} 2$ \\
\hline DZ192 & IRGC 8518 & $\mathrm{R}$ & Sokan Dhan & IRGC 16250 & $\mathrm{R}$ \\
\hline DZ78 & IRGC 8555 & $\mathrm{R}$ & Tepi Boro & IRGC 27519 & $\mathrm{~S} 1$ \\
\hline
\end{tabular}

${ }^{a}$ IRBB5 has an Aus-Boro introgression containing xa5 in an IR24 (Indica) background. 
units, and it is 85 to $93 \%$ identical to the Arabidopsis, maize, wheat, barley, and sugarcane genes. Most plant species appear to contain a TFIIA $\gamma$ that conforms to the susceptible allele model in rice, with a valine or leucine at position 39. Interestingly, yeast contains only one copy of TFIIA $\gamma$ (Aoyagi and Wassarman 2000), encoding a functional protein with a glutamic acid residue at the position corresponding to the resistant xa5 protein. While the yeast TFIIA $\gamma$ is only $39 \%$ identical to $\mathrm{xa} 5$, this critical point of comparison suggests that this mutation does not affect the essential function of TFIIA $\gamma$. Based on this comparative analysis and in keeping with our expression data, we hypothesize that TFIIA $\gamma$ functions both as a general transcription factor in rice and also as the $x a 5$ resistance gene.

To fully understand how the $x a 5$ gene product functions to confer resistance, the corresponding avirulence protein Avrxa5 must be considered. avrxa 5 has been localized to a cosmid that hybridizes to genes that encode members of the AvrBs3 family of effector proteins (Hopkins et al. 1992) and restores avirulence to a $X$. oryzae pv. oryzae mutant virulent on IRBB5 (Bai et al. 2000). The proteins of the AvrBs3 family share 90 to 97\% identity and have nuclear localization signals and an acidic activation domain (AAD) (Bonas and Lahaye 2002). In seeking to understand how TFIIA $\gamma$, as xa5, recognizes Avrxa5, it is interesting to note that the AAD of herpes simplex virus VP16 has been shown to interact with TFIIA $\gamma$ in a coimmunoprecipitation assay (Kobayashi et al. 1995), though there is no reported association between this interaction and pathogenicity. Furthermore, several lines of evidence suggest that members of the AvrBs3 family are transcription factors. AvrXa7, another X. oryzae Avr protein in this family, has been shown to bind double-stranded DNA (Yang et al. 2000) while Marois and associates (2002) demonstrated that the $X$. campestris AvrBs3 effector specifically up-regulates pepper genes during infection.

Rice, like Drosophila spp., has two copies of TFIIA $\gamma$ in its genome. One copy corresponds to $x a 5$ on chromosome 5 and the second to rice chromosome 1 (TFIIA $\gamma 1$ ). The location of these two copies corresponds to a large-scale duplication of a portion of chromosome 1 and chromosome 5 (Moore et al. 1995). TFIIA $\gamma 1$ is $85.8 \%$ identical to TFIIA $\gamma 5$ and is longer by three amino acids. TFIIA $\gamma 1$ has the susceptible haplotype and is expressed at lower levels than $x a 5$ in adult plant leaves (data not shown). It will be intriguing to investigate the genetic interactions that may exist between this gene and $x a 5$ and whether these may help explain the recessive nature of $x a 5$.

Indeed, although $x a 5$ is genetically defined as recessive, controversy exists regarding its recessive action. Li and associates (2001) reported that $x a 5$ was partially dominant, as F1 individuals from an IR2 $4 \times$ IRBB5 cross had lesion lengths intermediate between the two parents for all $X$. oryzae pv. oryzae races except Philippines race 4 . However, Blair and associates (2003) reported no significant difference in lesion length between the susceptible parent and heterozygotes of the same cross. Recent data from our lab (A. S. Iyer and S. R. McCouch, unpublished data) suggests that F1 heterozgyotes may have an intermediate lesion length but that this length is highly variable. More quantitative assays should shed light on this issue.

The potential dose-dependence suggests at least two interesting models for $x a 5$ action. In one scenario, the resistance allele product of $x a 5$ interacts with the AAD of Avrxa5. This could impede subsequent host cell transcription, disrupt normal cellular processes, and result in rapid cell death and resistance. In the absence or with a lower dose of xa5, Avrxa5 would also act as a transcription factor by directly binding to promoters of rice genes involved in susceptibility. Thus, xa5 would be haplo-insufficient and resistance dose-dependent.
Because, in xa5xa5 plants, twice as much xa5 would be accessible to interact with the avirulence protein, less Avrxa5 would be available to bind to promoters of genes involved in susceptibility. Thus in these plants, defense responses would be initiated before disease began and the xa5 and Avrxa5 interaction would result in complete resistance. Under this hypothesis, heterozygotes would be moderately susceptible, because they would not express enough of the resistance allele gene product for the interaction with Avrxa5 to initiate rapid defense responses. Thus, in Xa5xa5 individuals, sufficient Avrxa5 would be able to bind to susceptibility promoters to cause disease. In this case, heterozygotes might be expected to support less bacteria and have smaller average lesion lengths. In Xa5Xa5 plants, Avrxa5 would initiate disease by binding directly to susceptibility gene promoters.

It is also possible that xa5 is the virulence target of Avrxa5. Avrxa5 could enter the nucleus and interact with either the susceptible or resistant gene product; this interaction could occur through the putative AAD of Avrxa5. Avrxa5 could then direct TFIIA $\gamma$ to promoters involved in susceptibility, consistent with the gene-specific regulation function of TFIIA found in Drosophila spp. (Aoyagi and Wassarman 2000; Upadhyaya et al. 1999; Zeidler et al. 1996). This model fits in well with the guard hypothesis, which states that $R$ genes such as NBSLRRs 'guard' the host cell virulence targets of Avr proteins (van der Biezen and Jones 1998). These guards detect the interaction between the Avr and virulence protein targets and respond by initiating a signaling pathway that leads to resistance. If a third protein were involved here, presumably an NBS-LRR, it is possible that this third protein would recognize the interaction between xa5 and Avrxa5, initiating defense responses. This additional gene is predicted to be the same in both the susceptible IR24 and resistant IRBB5 isolines. In this model, $x a 5$ resistance would again be dose-dependent. In heterozygous plants, both resistant and susceptible allele products would interact with Avrxa5. However, the third protein would not recognize the interaction between Avrxa5 and the susceptible allele product Xa5. Avrxa5 would direct Xa5 to promoters of susceptibility genes, but this would compete with the recognition of the xa5-Avrxa5 interaction by the NBS-LRR. Resistance signaling would either not occur quickly enough or would not have the intensity to prevent disease. In xa5xa5 plants, without competition from susceptibility factors, the third protein would efficiently initiate defense responses, leading to a recessive form of disease resistance. Understanding which of these mechanisms underlies this atypical form of disease resistance awaits, in part, the cloning of avrxas and subsequent protein interaction experiments.

In this report, we have shown that the rice $x a 5$ disease $R$ gene product for bacterial blight encodes a gamma subunit of TFIIA. It is tempting to speculate that such a ubiquitous protein may hold answers to disease processes in animals as well as in plants.

\section{MATERIALS AND METHODS}

\section{Recombinant screen.}

A total of 2,345 individuals from an F2 population of a cross between the susceptible indica variety IR24, containing $\mathrm{Xa5}$, and the resistant isoline IRBB5, which has an introgression containing xa5 (Ogawa et al. 1988), were grown in 2-inch deepots in the Guterman greenhouse of Cornell University. DNA was extracted using the Matrix Mill method (Paris and Carter 2000). The microsatellites RM601, RM603, RM607, RM609, and RM611 (Blair et al. 2003) were amplified using standard PCR protocols, run on $4 \%$ polyacrylamide electrophoresis gels and silver-stained as described (Panaud et al. 1996). Tillers of 
recombinant $\mathrm{F} 2$ individuals were divided and transplanted into 6 -inch pots. One tiller was inoculated with $X$. oryzae pv. oryzae PXO 86 (race2), and one tiller was allowed to set seed.

A total of $20 \mathrm{~F} 3$ seeds from each recombinant F2 individual were planted, were inoculated 55 to 60 days after planting, and were analyzed for phenotype and segregation within a family. Reactions were scored as resistant if the average lesion length was $3 \mathrm{~cm}$ or less and as susceptible if average lesion length was greater than $3 \mathrm{~cm}$. Several plants of the cultivar Nipponbare were inoculated and scored in the same manner.

\section{Bacterial growth and inoculation.}

$X$. oryzae pv. oryzae PXO 86 was cultured on media containing $20 \mathrm{~g}$ of sucrose, $5 \mathrm{~g}$ of peptone, $0.5 \mathrm{~g} \mathrm{Ca}\left(\mathrm{NO}_{3}\right)_{2}, 0.43 \mathrm{~g}$ $\mathrm{Na}_{2} \mathrm{HPO}_{4}$, and $0.05 \mathrm{~g} \mathrm{FeSO}_{4}$ per liter and was allowed to grow at 28 to $30^{\circ} \mathrm{C}$ for 3 to 4 days. Bacteria were collected into sterile distilled water and adjusted to a concentration of an optical density at $600 \mathrm{~nm}=1$. Plants were inoculated by the leaf-clipping method (Kauffman et al. 1973) 55 to 65 days after planting and were scored 14 days after inoculation.

\section{RT-PCR.}

Tissue was collected from susceptible IR24 plants and its resistant isoline IRBB5 at 2, 4, 8, 24, and $48 \mathrm{~h}$ after inoculation in three separate experiments. Uninoculated and wounded plants were used as controls. Leaves were wounded by tearing a 2- to 3-cm piece of leaf tissue. Total RNA was extracted with RNAeasy miniplant RNA extraction kit (Qiagen, Valencia, CA, U.S.A.). Total RNA (1 $\mu \mathrm{g})$ was treated with DNAse (Invitrogen, Carlsbad, CA, U.S.A.) and was amplified into cDNA with reverse transcriptase (Invitrogen), following manufacturer's instructions. As a control, water was used in place of reverse transcriptase for the RT reaction. The reaction was diluted threefold and $2 \mu \mathrm{l}$ of cDNA was used for amplification of TFIIA $\gamma$ and actin; $4 \mu \mathrm{l}$ of cDNA was used for amplification of Q94HL4. A series of 20, 25, 30, 35, and 40 cycles was used for amplification. No product was seen in the RT reactions (data not shown). A total of $7 \mu \mathrm{l}$ of TFIIA $\gamma$, actin, and TFIIA $\gamma$ RT, and $15 \mu \mathrm{l}$ of Q94HL4 PCR products were loaded on $1 \%$ agarose gels. Primers were designed to span introns of TFIIAy5, Q94HL4, and actin; each reverse primer was anchored in the $3^{\prime}$ UTR. BLAST searches were used to ensure that primers were specific to the candidate gene of interest. The primers used were:

\section{TFIIA $\gamma$ F 5'-GAAGCCTTGGAGAACCAAGTC, TFIIA $\gamma$ R 5'-GGTGACTCCGCACAATTTCT; Q94HL4 F 5'-GCACCTTTATGGCCATCCCCACTAT, Q94HL4 R 5'-GGTATACATGTGCCGAAGGTC; actin $\mathrm{F}$ 5'-CGTCCTCTCTCTGTATGCCAG, actin $\mathrm{R}$ 5'-CTGGTACCCTCATCAGGCAT.}

\section{Sequence analysis of resistant and susceptible cultivars.}

Susceptible and resistant cultivars were chosen from the group of Aus-Boro rice varieties (Garris et al. 2003). Primers were designed at 0.5 - to $1-\mathrm{kb}$ intervals throughout the candidate gene region and were used to amplify susceptible and resistant sequences with PFU polymerase (Invitrogen, Carlsbad, CA, U.S.A.). Amplified products were sequenced at the Cornell Biotechnology Resource Center.

\section{Database searches and sequence alignment.}

Databases at The National Center for Biotechnological Information and The Institute for Genome Research were searched using BLAST (Altschul et al. 1997). Sequences were aligned using the ClustalW program of the European Bioinformatics Institute and the MegAlign program of DNAstar (GeneCodes, Ann Arbor, MI, U.S.A.). We used previously reported gene pre- diction (Blair et al. 2003) and mRNA (GI 33151122) alignment to genomic IR24 sequence to find the first codon of the gene encoding the hypothetical protein Q94HL4.

\section{ACKNOWLEDGMENTS}

We thank R. Abramovitch, J. Anderson, J. Edwards, G. Martin, and P. Pascuzzi for critical reading of the manuscript, M. Blair for the F2 population, and L. Swales for administrative assistance. This material is based upon work supported by the Cooperative State Research, Education, and Extension Service, United States Department of Agriculture under Agreement No. 2003-35301-13130. A. Iyer was supported by National Needs Fellowship USDA No. 98-38420-5812.

\section{LITERATURE CITED}

Altschul, S. F., Thomas L. Madden, Alejandro A. Schäffer, and Jinghui Zhang, Z. Z., Webb Miller, and David J. Lipman. 1997. Gapped BLAST and PSI-BLAST: A new generation of protein database search programs. Nucleic Acids Res. 25:3389-3402.

Aoyagi, N., and Wassarman, D. A. 2000. Genes encoding Drosophila melanogaster RNA polymerase II general transcription factors: Diversity TFIIA and TFIID components contributes to gene-specific transcriptional regulation. J. Cell Biol. 150:F45-50.

Bai, J., Choi, S. H., Ponciano, G., Leung, H., and Leach, J. E. 2000. Xanthomonas oryzae pv. oryzae avirulence genes contribute differently and specifically to pathogen aggressiveness. Mol. Plant-Microbe Interact. 13:1322-1329.

Blair, M. W., and McCouch, S. R. 1997. Microsatellite and sequencetagged site markers diagnostic for the rice bacterial leaf blight resistance gene $x a-5$. Theor. Appl. Genet. 95:174-184.

Blair, M. W., Garris, A. J., Iyer, A. S., Chapman, B., Kresovich, S., and McCouch, S. R. 2003. High resolution genetic mapping and candidate gene identification at the xa5 locus for bacterial blight resistance in rice (Oryza sativa L.). Theor. Appl. Genet. 107:62-73.

Bleichenbacher, M., Tan, S., and Richmond, T. J. 2003. Novel interactions between the components of human and yeast TFIIA/TBP/DNA complexes. J. Mol. Biol. 332:783-793.

Bonas, U., and Lahaye, T. 2002. Plant disease resistance triggered by pathogen-derived molecules: Refined models of specific recognition. Curr. Opin. Microbiol. 5:44-50.

Buschges, R., Hollricher, K., Panstruga, R., Simons, G., Wolter, M., Frijters, A., van Daelen, R., van der Lee, T., Diergaarde, P., Groenendijk, J., Topsch, S., Vos, P., Salamini, F., and Schulze-Lefert, P. 1997. The barley Mlo gene: A novel control element of plant pathogen resistance. Cell 88:695-705.

Deslandes, L., Olivier, J., Theulieres, F., Hirsch, J., Feng, D. X., BittnerEddy, P., Beynon, J., and Marco, Y. 2002. Resistance to Ralstonia solanacearum in Arabidopsis thaliana is conferred by the recessive RRS1$R$ gene, a member of a novel family of resistance genes. Proc. Natl. Acad. Sci. U.S.A. 99:2404-2409.

Deslandes, L., Olivier, J., Peeters, N., Feng, D. X., Khounlotham, M., Boucher, C., Somssich, I., Genin, S., and Marco, Y. 2003. Physical interaction between RRS1-R, a protein conferring resistance to bacterial wilt, and PopP2, a type III effector targeted to the plant nucleus. Proc. Natl. Acad. Sci. U.S.A. 100:8024-8029.

Flor, H. H. 1971. Current status of the gene-for-gene concept. Annu. Rev. Phytopathol. 9:275-296.

Garris, A. J., McCouch, S. R., and Kresovich, S. 2003. Population structure and its effect on haplotype diversity and linkage disequilibrium surrounding the xa5 locus of rice (Oryza sativa L.) Genetics 165:759-769

Hampsey, M. .1998. Molecular genetics of the RNA polymerase II general transcriptional machinery. Microbiol. Mol. Biol. Rev. 62:465-503.

Hopkins, C. M., White, F. F., Choi, S. H., Guo, A., and Leach, J. E. 1992. Identification of a family of avirulence genes from Xanthomonas oryzae pv. oryzae. Mol. Plant. Microbe Interact. 5:451-459.

Higo, K. U., Y; Iwamoto, M; Korenaga, T 1999. Plant cis-acting regulatory DNA elements (PLACE) database: 1999. Nucleic Acids Res. 27:297300 .

Li, Z. K., Sanchez, A., Angeles, E., Singh, S., Domingo, J., Huang, N., and Khush, G. S. 2001. Are the dominant and recessive plant disease resistance genes similar?: A case study of rice $R$ genes and Xanthomonas oryzae pv. oryzae races. Genetics 159:757-765.

Kauffman, H. E., Reddy A. P. D., Ksiek, S. P. V., and Marca, S. D. 1973. An improved technique for evaluating resistance of race varieties to Xanthomonas oryzae. Plant Dis. Rep. 57:537-541.

Kobayashi, N., Boyer, T. G., and Berk, A. J. 1995. A class of activation domains interacts directly with TFIIA and stimulates TFIIA-TFIID-pro- 
moter complex assembly. Mol. Cell. Biol. 15:6465-6473.

Marois, E., Van den Ackerveken, G., and Bonas, U. 2002. The Xanthomonas type III effector protein AvrBs3 modulates plant gene expression and induces cell hypertrophy in the susceptible host. Mol. PlantMicrobe Interact. 15:637-646.

Martin, G. B., Bogdanove, A. J., and Sessa, G. 2003. Understanding the Functions of plant disease resistance proteins. Annu. Rev. Plant Physiol. Plant. Mol. Biol. 54:23-61.

Moore, G., Devos, K. M., Wang, Z., and Gale, M. D. 1995. Cereal genome evolution. Grasses, line up and form a circle. Curr. Biol. 5:737-9.

Ogawa, T., Yamamoto, T., Khush, G. S., Mew, T. W., and Kaku, H. 1988. Near-isogenic lines as international differentials for resistance to bacterial blight of rice. Rice Genetics Newsl. 5:106-109.

Olufowote, J. O., Khush, G.S., and Kauffamn, H.E. 1977. Inheritance of bacterial blight disease in rice. Phytopathology 67:772-775.

Orphanides, G., Lagrange, T., and Reinberg, D. 1996. The general transcription factors of RNA polymerase II. Genes Dev. 10:2657-2683.

Panaud, O., Chen, X., and McCouch, S. R. 1996. Development of microsatellite markers and characterization of simple sequence length polymorphism (SSLP) in rice (Oryza sativa L.). Mol. Gen. Genet. 252:597607.

Paris, M., and Carter, M. 2000. Cereal DNA: A rapid thigh-throughput extraction method for marker assisted selection. Plant Mol. Biol. Rep. 18:357-360

The Rice Chromosome 10 Sequencing Consortium. 2003. In-depth view of structure, activity, and evolution of rice chromosome 10 . Science 300:1566-1569.

Sidhu, G. S., Khush, G. S., Mew T. W. 1978. Genetic analysis of bacterial blight resistance in seventy-four cultivars of rice, Oryza sativa L. Theor. Appl. Genet. 53:105-111.

Singh, R. J., Khush, G. S., Mew T. W. 1983, A new gene for resistance to bacterial blight in rice. Crop Sci. 23:558-560.

Song, W.-Y., Wang, G.-L., Chen, L.-L., Kim, H.-S., Pi, L.-Y., Holsten, T., Gardner, J., Wang, B., Zhai, W.-X., Zhu, L.-H., Fauquet, C., and Ronald, P. 1995. A receptor kinase-like protein encoded by the rice disease resistance gene, $\mathrm{Xa21}$. Science 270:1804-1806.

Sun, X., Cao, Y., Yang, Z., Xu, C., Li, X., Wang, S., and Zhang, Q. 2004. Xa26, a gene resistance to Xanthomonas oryzae pv. oryzae in rice, encodes an LRR receptor kinase-like protein. Plant J. 37:517-527.

Upadhyaya, A. B., Lee, S. H., and DeJong, J. 1999. Identification of a general transcription factor TFIIA alpha/beta homolog selectively expressed in testis. J. Biol. Chem. 274:18040-18048.

van der Biezen E. A and Jones J. D. 1998. Plant disease-resistance proteins and the gene-for-gene concept. Trends Biochem. Sci. 23:454-456.

Yang, B., Zhu, W., Johnson, L. B., and White, F. F. .2000. The virulence factor AvrXa7 of Xanthomonas oryzae pv. oryzae is a type III secretion pathway-dependent nuclear-localized double-stranded DNA-binding protein. Proc. Natl. Acad. Sci. U.S.A. 97:9807-9812.

Yoshimura, S., Yamanouchi, U., Katayose, Y., Toki, S., Wang, Z. X., Kono, I., Kurata, N., Yano, M., Iwata, N., and Sasaki, T.1998. Expression of $\mathrm{Xa1}$, a bacterial blight-resistance gene in rice, is induced by bacterial inoculation Proc. Natl. Acad. Sci. U.S.A 95:1663-1668.

Zeidler, M. P., Yokomori, K., Tjian, R., and Mlodzik, M. 1996. Drosophila TFIIA-S is up-regulated and required during Ras-mediated photoreceptor determination. Genes Dev. 10:50-59.

\section{AUTHOR-RECOMMENDED INTERNET RESOURCES}

European Bioinformatics Institute, ClustalW program: www.ebi.ac.uk International Rice Information System database:

www.iris.irri.org/icis/SearchIRIS.htm 